\title{
Pelvic inflammatory disease: improving awareness, prevention, and treatment
}

\section{Breanne B Das \\ Jocelyn Ronda \\ Maria Trent}

Division of General Pediatrics and Adolescent Medicine, Johns Hopkins University School of Medicine,

Baltimore, MD, USA
Correspondence: Maria Trent Division of General Pediatrics and Adolescent Medicine, Johns Hopkins University School of Medicine, 200 North Wolfe Street, Number 2064, Baltimore, MD 21287, USA

Tel + I 4432878945

Fax + I 4105025440

Email mtrent2@jhmi.edu
This article was published in the following Dove Press journal:

Infection and Drug Resistance

19 August 2016

Number of times this article has been viewed

Purpose: Pelvic inflammatory disease (PID) is a common disorder of the reproductive tract that is frequently misdiagnosed and inadequately treated. PID and its complications, such as infertility, ectopic pregnancy, and chronic pelvic pain, are preventable by screening asymptomatic patients for sexually transmitted infections (STIs) and promptly treating individuals with STIs and PID. Recent findings: The rates of adverse outcomes in women with PID are high and disproportionately affect young minority women. There are key opportunities for prevention including improving provider adherence with national screening guidelines for STIs and PID treatment recommendations and patient medication adherence. Nearly half of all eligible women are not screened for STIs according to national quality standards, which may increase the risk of both acute and subclinical PID. Moreover, in clinical practice, providers poorly adhere to the Centers for Disease Control and Prevention recommendations for treatment of PID. Additionally, patients with PID struggle to adhere to the current management strategies in the outpatient setting.

Conclusion: Novel evidence-based clinical and public health interventions to further reduce the rates of PID and to improve outcomes for affected women are warranted. We propose potential cost-effective approaches that could be employed in real-world settings.

Keywords: pelvic inflammatory disease, treatment, disparities

\section{Introduction}

In the US, $\sim 800,000$ women are diagnosed with pelvic inflammatory disease (PID) each year. ${ }^{1}$ However, the US Centers for Disease Control and Prevention (CDC) estimates that more than one million women experience an episode of PID each year taking into account missed cases of PID. ${ }^{2}$ The rates of PID are concerning given the serious potential sequelae of PID, including tubal infertility, ectopic pregnancy, and chronic pelvic pain (CPP). Missed and/or improperly or inadequately treated cases of PID increase the risk of complications of PID. ${ }^{3}$ Not only does the severity of these complications highlight the seriousness of the disorder, but also young women indicated that they are willing to give up 1-2 years of their life to prevent PID and its associated sequelae, as reported in a recent health economics study using time trade offs to assess patient utilities for the health states associated with PID in a general population sample. ${ }^{4}$

PID is an infection of the female upper reproductive tract, including the endometrium, fallopian tubes, ovaries, and pelvic peritoneum. ${ }^{5}$ Sexually transmitted infections (STIs), such as Chlamydia trachomatis and Neisseria gonorrhoeae, are commonly implicated in cases of PID, but they are not the only organisms associated with clinical disease. The diagnosis of PID is made difficult by variation in clinical manifestations: subclinical patients with PID are asymptomatic, while patients with more severe disease 
present with abdominal pain requiring surgical intervention. , $^{6}$ Subclinical PID is defined as inflammation of the upper reproductive tract in the absence of signs and symptoms of acute PID. ${ }^{7}$ According to the CDC 2015 Sexually Transmitted Diseases Treatment Guidelines, any young sexually active woman or woman at risk for STIs with unexplained lower abdominal or pelvic pain and at least one of the following clinical criteria noted on pelvic examination should receive presumptive treatment for PID: cervical motion tenderness, uterine tenderness, and adnexal tenderness (Table 1). ${ }^{8}$ In this review, we aim to discuss the current state of PID management and propose new strategies for optimal management.

\section{Awareness}

Data from the National Survey of Family Growth (NSFG) from 2006 to 2010 showed that $5.0 \%$ of women reported being treated for PID in their lifetime. ${ }^{9}$ Using secondary analysis of data from the PID Evaluation and Clinical Health (PEACH) study (a multicenter, randomized control trial designed to compare outpatient and inpatient treatment regimens in women with $\mathrm{PID}^{7}$ ) conducted by Trent et al, ${ }^{10}$ reported that 7 years after a diagnosis of PID, $21.3 \%$ of women experienced recurrent PID, 19.0\% developed infertility, and $42.7 \%$ of women reported having CPP. The study of PID in younger populations has revealed that adolescents are at even greater risk of developing PID and associated complications. An estimated one in five cases of PID occur in women younger than 19 years, and in one study, adolescents and young women aged 17-21 years were twice as likely as other age groups to be diagnosed with PID. ${ }^{11,12}$ The increased risk of PID in adolescents is thought to be secondary to a combination of behavioral and biological factors. ${ }^{13}$ In terms of behavioral risk, adolescents are likely to have multiple sex partners, engage in unprotected sex, and have short duration and high frequency monogamous relationships. ${ }^{14}$ Biologically, adolescents have a greater proportion of surface area for microorganisms to infect. ${ }^{13,15}$ Trent et al also found in the PEACH study that adolescents aged $\leq 19$ years with recurrent PID were five times more likely to report CPP 7 years after being diagnosed with PID. Additionally, adolescents in the PEACH study developed recurrent PID in a shorter period of time than adult women. ${ }^{10}$

There are also significant health disparities associated with PID. ${ }^{16-21}$ Sutton et $\mathrm{al}^{1}$ found that the rates of PID diagnosis in black women were two to three times greater than those in white women in hospital and ambulatory settings. Consistent with this racial disparity, Goyal et al ${ }^{12}$ more recently found that race was associated with a diagnosis of PID in adolescent patients evaluated in the emergency department. Furthermore, a retrospective analysis of the NSFG from 2006 to 2010 showed that women with an income of $<150 \%$ of the federal poverty level as measured by the US census ${ }^{22}$ and less than a high school education have the highest self-reported frequency of PID treatment. ${ }^{23}$

\section{Prevention}

Prevention of PID falls broadly into the following two categories: 1) prevention of the first PID episode and 2) prevention of recurrent disease. Women who have had one episode of PID need to prevent STI infection given the relationship between recurrent STIs, such as C. trachomatis and infertility. ${ }^{24}$ Prevention of the first episode of PID requires early diagnosis of STIs and therefore improved provider adherence to the United States Preventive Screening Task Force and CDC guidelines. In the 2015 Sexually Transmitted Diseases Treatment Guidelines, the CDC recommends

Table I PID diagnostic criteria per 2015 CDC guidelines

\begin{tabular}{ll}
\hline Minimal clinical criteria ${ }^{\mathrm{a}}$ & Cervical motion tenderness \\
& Uterine tenderness \\
& Adnexal tenderness \\
& Oral temperature greater than $10 I^{\circ} \mathrm{F}\left(38.3^{\circ} \mathrm{C}\right)$ \\
& Abnormal cervical mucopurulent discharge or cervical friability \\
& Abundant white blood cells on microscopic evaluation of vaginal fluid \\
& Elevated erythrocyte sedimentation rate \\
& Elevated C-reactive protein \\
& Laboratory documentation of cervical infection with Neisseria gonorrhoeae or Chlamydia trachomatis \\
& Endometrial biopsy with histopathologic evidence of endometritis \\
& Transvaginal ultrasound or magnetic resonance imaging showing thickened, fluid-filled tubes with or without free \\
Specific criteriac & pelvic fluid or tubo-ovarian complex, or Doppler studies suggesting pelvic infection \\
& Laparoscopic findings consistent with PID
\end{tabular}

Notes: Reproduced from CDC. 2015 Sexually Transmitted Diseases Treatment Guidelines. Atlanta, GA: Department of Health and Human Services; $2015 .{ }^{3}$ alnitiate treatment if one or more of these criteria are met. 'ln addition to one or more minimal criteria, one or more of the additional criteria increases specificity of the diagnosis of PID. ${ }^{\circ}$ One or more of these criteria provides the most specific diagnosis of PID.

Abbreviations: CDC, US Centers for Disease Control and Prevention; PID, pelvic inflammatory disease. 
annual chlamydia and gonorrhea screening in all sexually active women younger than 25 years of age and in sexually active women 25 years of age and older at increased risk defined as women who have a new sex partner, those who have more than one sex partner, those whose sex partner has concurrent partners, or those with a sex partner who has an STI. ${ }^{25}$ The CDC also recommends considering regular screening for Trichomonas vaginalis in women receiving care in high STI prevalence settings and women engaged in high risk behaviors, such as sex with multiple partners, exchanging sex for money or drugs, use of illicit drugs, and prior history of an STI. Women who test positive for an STI should be rescreened for STIs 3 months after STI treatment, particularly if they reside in STI-prevalent communities and/ or new behavioral risks are identified at the follow-up visit. ${ }^{8}$ Randomized control trials of women diagnosed with $C$. trachomatis suggest that screening can lead to a reduction in PID incidence. ${ }^{26,27}$ Unfortunately, physicians have largely failed to screen eligible women according to national standards. An analysis of the NSFG from 2006 to 2010 estimates that $40 \%$ of sexually active US women aged $15-21$ years were screened for C. trachomatis. ${ }^{28}$ Additional concern is raised for newly recognized STIs, such as Mycoplasma genitalium, for which commercial testing is not yet available in the US. Several studies have demonstrated that both $T$. vaginalis and M. genitalium are associated with PID. ${ }^{29,30}$ Not only does failure of asymptomatic STI screening lead to inadvertent spreading of and increasing the national burden of STIs, but also untreated STIs predispose women to PID.

Screening and early treatment of STIs can also decrease the incidence of subclinical PID, which has similar morbidity to acute PID. The exact incidence of subclinical PID is difficult to determine, but studies have suggested that incidence is high. In a cross-sectional study, using endometrial biopsies of women diagnosed with or at risk for STIs in clinical settings, Wiesenfeld et $\mathrm{a}^{31}$ detected subclinical PID in $26 \%$ of women with Neisseria gonorrhoeae and $27 \%$ of women with $C$. trachomatis. Biopsy specimens demonstrate that subclinical PID may be as destructive to fallopian tubes as acute symptomatic PID ${ }^{32}$ and is also associated with infertility. ${ }^{7}$ Given that subclinical PID lacks overt clinical signs and symptoms, asymptomatic STI screening and early treatment are critical.

Prevention of recurrent PID is also a public health priority. It is well established that patients with recurrent PID are at risk for greater reproductive sequelae than those who avoid subsequent disease. Using a Scandinavian inpatient cohort of patients diagnosed with PID between 1960 and 1984 , Weström et $\mathrm{a}^{133}$ found that infertility roughly doubles with each subsequent episode of PID. Similarly, using data from the PEACH study, Trent et a $1^{10}$ found that women with recurrent PID were almost two times more likely to report infertility and over four times more likely to report CPP.

Among women with PID, recurrent disease is not uncommon. Data from the PEACH study shows that $<3$ years after initial PID diagnosis, $14.5 \%$ of participants had recurrent PID, and at 7 years, $>21 \%$ had repeat PID. ${ }^{34}$ These data suggest that additional efforts to implement clinical interventions aimed at adequate treatment and prevention of recurrent disease are warranted.

\section{Treatment}

Damage to the female reproductive tract from PID is usually irreversible; therefore, prompt antibiotic treatment is necessary to prevent any scarring of the reproductive tract. ${ }^{35}$ Treatment of PID per CDC guidance includes broad spectrum antibiotic coverage (Table 2). Parenteral and oral antibiotic regimens have been found to have similar efficacy in women with mild to moderately severe PID, ${ }^{36,37}$ and Smith et al ${ }^{38}$

Table 2 PID antibiotic regimens per 2015 CDC PID treatment guidelines

\begin{tabular}{|c|c|}
\hline \multicolumn{2}{|c|}{ Parenteral treatment $^{a}$} \\
\hline Regimen A & CeFotetan 2 g IV every 12 hours + doxycycline 100 mg PO or IV every 12 hours \\
\hline Regimen B & CeFoxitin 2 g IV every 6 hours + doxycycline 100 mg PO or IV every 12 hours \\
\hline Regimen C & $\begin{array}{l}\text { Clindamycin } 900 \mathrm{mg} \text { IV every } 8 \text { hours }+ \text { gentamicin } 2 \mathrm{mg} / \mathrm{kg} \text { loading dose IV or IM followed by } 1.5 \mathrm{mg} / \mathrm{kg} \text { every } 8 \text { hours (can } \\
\text { substitute single daily dosage of } 3-5 \mathrm{mg} / \mathrm{kg} \text { ) }\end{array}$ \\
\hline Alternate regimen & Ampicillin/sulbactam $3 \mathrm{~g} I V$ every 6 hours + doxycycline $100 \mathrm{mg}$ orally or IV every 12 hours \\
\hline \multicolumn{2}{|l|}{ Oral treatment } \\
\hline Regimen A & $\begin{array}{l}\text { CeFtriaxone } 250 \mathrm{mg} \text { IM in a single dose + doxycycline } 100 \mathrm{mg} \text { PO BID for } 14 \text { days } \pm \text { metronidazole } 500 \mathrm{mg} \text { PO BID for } \\
\text { I4 days }\end{array}$ \\
\hline Regimen B & $\begin{array}{l}\text { CeFoxitin } 2 \mathrm{~g} \mathrm{IM} \text { and probenecid I } \mathrm{g} \text { PO in a single dose + doxycycline } 100 \mathrm{mg} \text { PO BID for } 14 \text { days } \pm \text { metronidazole } 500 \mathrm{mg} \\
\text { PO BID for I4 days }\end{array}$ \\
\hline Regimen C & A Third-generation cephalosporin + doxycycline $100 \mathrm{mg}$ PO BID for 14 days \pm metronidazole $500 \mathrm{mg}$ PO BID for 14 days \\
\hline
\end{tabular}

Notes: Reproduced from CDC. 2015 Sexually Transmitted Diseases Treatment Guidelines. Atlanta, GA: Department of Health and Human Services; $2015 .{ }^{3}$ Trials have shown short-term clinical effectiveness with monotherapy azithromycin $500 \mathrm{mg}$ IV daily for one or two doses $+250 \mathrm{mg}$ PO for 5-6 days, or combined with a 12 -day course of metronidazole. ${ }^{67,68}{ }^{2}$ Continuation of parenteral regimens for 24 hours after clinical improvement then transition to oral regimen to complete the 14-day treatment course. Abbreviations: BID, twice daily; CDC, US Centers for Disease Control and Prevention; IM, intramuscular; IV, intravenous; PID, pelvic inflammatory disease; PO, by mouth. 
demonstrate that inpatient hospitalization for the treatment of PID is not economically feasible; therefore, the CDC recommends oral regimens in this subgroup of patients in the outpatient setting. Inpatient treatment is recommended for patients who meet any of the following criteria: 1) unable to exclude a surgical emergency, 2) tubo-ovarian abscess, 3) pregnancy, 4) severe illness (eg, nausea, vomiting, and high fever), 5) inability to tolerate outpatient regimen, and 6) failure to respond to oral regimen with persistent and/or worsening symptoms. All patients should be reevaluated by a clinician within 72 hours after initiating treatment. Additional evaluation and/or hospitalization for parenteral antibiotics may be indicated for patients who do not show clinical improvement at this time. Male sexual partners from the last 60 days should be evaluated, tested, and treated for C. trachomatis and GC.

The 72-hour visit is critically important to assess the clinical status of the patient, particularly given the rise in multidrug-resistant $N$. gonorrhoeae. The spread of cephalosporin-resistant $G C$ is estimated to lead to an additional 75,000 cases of PID over a 10-year period. ${ }^{39}$ These clinical scenarios are likely to be more complicated since they cannot be easily treated, further increasing the potential for reproductive health sequelae.

While the CDC no longer recommends differential treatment for adolescents, ${ }^{8}$ there are limited data to support the management of early and middle adolescents in the outpatient setting. The mean age of adolescents in the PEACH study cohort was 18 years (SD 1 year). ${ }^{34}$ While providers struggle with the disposition plans for adolescents, ${ }^{40}$ careful consideration of developmental status, social support, and actual ability to follow or tolerate an outpatient regimen should guide these decisions. ${ }^{3}$

Provider adherence to CDC treatment guidelines in the US is poor. ${ }^{41}$ In an analysis of quality improvement data from pediatric ambulatory settings within a single urban institution, Trent et $\mathrm{al}^{42}$ found that only $62 \%$ of patients received treatment according to national standards. An analysis of the National Hospital Ambulatory Medicare Care Survey data from 2000 to 2009 suggests a more dire national picture. Of 704,882 females aged 14-21 years diagnosed with PID in US emergency departments, only $37.1 \%$ were prescribed antibiotics that adhered to the CDC guidelines. ${ }^{43}$ Even more concerning results were seen in an analysis by Woods et $\mathrm{al}^{44}$ in which only $6 \%$ of subjects who met diagnosis criteria of PID were correctly treated with appropriate coverage in an outpatient setting. Woods et $\mathrm{al}^{44}$ cite a disconnect between theoretical concepts and real-world applications and low overall knowledge of PID as causes of poor provider adherence to
CDC treatment guidelines. Two studies, however, have demonstrated that with provider education, provider adherence to CDC guidelines can improve. ${ }^{45}$

Even when providers prescribe the regimens according to national standards, patients are unlikely to strictly adhere to the prescribed treatment regimens. In an analysis using the PEACH study data, Dunbar-Jacob et al found that on average, patients with PID in the study took only $70 \%$ of the prescribed doses of medication. More specifically, patients in the PEACH study did not take any medication on $\sim 25 \%$ of their outpatient days and took medications twice daily as prescribed less than half of their outpatient treatment days. Additionally, the patients in the PEACH study took $<17 \%$ of their doses within 11-13 hours of the previous dose for the twice daily treatment regimen. ${ }^{46}$ Dunbar-Jacob et al ${ }^{46}$ associate poor patient adherence with the length of the antibiotic course and frequency of dosing and suggest that shorter courses of less frequent dosing may improve adherence. In a study by Trent et al, ${ }^{42}$ patients reported additional reasons for low adherence to medication regimens, including vomiting, loss of medication, and being told by the primary care physician to stop because of negative cultures. Patients also have difficulty adhering to recommendations to follow-up with 72 hours of diagnosis. In a study of urban adolescents, only $10 \%$ of adolescents with PID returned for follow-up evaluations within 72 hours. ${ }^{42}$ After an institutional intervention in the same setting that included provider education and treatment algorithm, provision of a 14-day course of antibiotics at discharge, detailed written discharge instructions, and telephone follow-up, 61\% of adolescents reported completed all doses of the medication, $67 \%$ practiced temporary abstinence, and $86 \%$ notified their partner for treatment. ${ }^{42}$ The authors reported that the patients' reasons for lack of follow-up included not being aware of the need to follow-up, no access to transportation, inability to get an appointment, and lack of a primary care provider. ${ }^{42}$

\section{New directions}

The current state of PID management approach to treatment is highly focused on self-management in outpatient settings. The use of inpatient hospitalization is expensive and simply no longer a cost-effective strategy for all women. ${ }^{47}$ There may be, however, alternative strategies that optimize the use of clinical services while continuing to reduce the cost of PID care delivery. Two potential strategies worth consideration include observation units (OUs) and community health nursing.

OUs are units within or adjacent to emergency departments where patients are admitted when they require additional 
diagnostics or therapies, but discharge is anticipated within 24 hours. $^{48}$ The OU model has been found to have many benefits, including improved patient care, decreased hospital admissions, cost effectiveness, and improved emergency department efficiency. ${ }^{49}$ The model of OUs has been applied to a variety of conditions, including chest pain, asthma, skin infections, and allergic reactions, and has been shown to be effective in several studies. ${ }^{50-53}$ OUs are increasingly being recognized as effective treatment strategies, and the use of observation status by Medicare beneficiaries increased by $26 \%$ from 2006 to $2008 .{ }^{54}$ In order to reimburse for OU care, the Centers for Medicare and Medicaid Services require an observation time of at least 8 hours, ${ }^{55}$ with a maximum of 48 hours in most circumstances ${ }^{56}$ OUs have been shown to be effective in both the pediatric and adult populations. Lane et $\mathrm{al}^{57}$ performed a retrospective review of 853 patients younger than 18 years admitted for skin and soft tissue infection treatment to an OU from the emergency department between January 2003 and June 2009. Seventy percent had successful OU discharge within 26 hours. Similarly, in a randomized clinical trial of 222 patients with asthma aged 18-55 years comparing treatment outcomes in an OU and an inpatient setting, similar patients treated in an OU had asthma relapse and other morbidity rates at 8 weeks equivalent to that of patients treated with standard inpatient therapy, and cost, patient satisfaction, and quality of life outcomes favored the OU approach. ${ }^{58} \mathrm{OU}$ has been an effective model for a variety of conditions in both the pediatric and adult populations, including infectious disease, which suggests that this treatment model holds promise for the management of PID. In regard to PID, OUs are likely to be more cost effective than inpatient hospitalization and could allow for significant benefits regarding medication administration, consultation, patient education, and risk reduction counseling for prevention of recurrent disease. Observing patients during a short 12-hour period allows for two medication doses to be delivered, adequate counseling, mobilization of support, and assistance with prescription filling in large institutional settings. Given the increased length of stay over the emergency department for PID care, the patient's visit would likely overlap in time with the daytime staff allowing for greater access to resources, such as social work services, HIV counseling and testing, and risk reduction counseling services. However, clinical care in OUs should be time efficient because longer clinical encounters are associated with a decline in subsequent medication adherence. In a study of adolescents treated for PID in the emergency department, Hill et $\mathrm{al}^{59}$ found that patients with above average length of service were significantly less adherent with their PID medications than patients with less than average length of service. Health service research is needed to evaluate the effectiveness of utilizing OUs for treatment of PID with concurrent cost analyses.

Another promising strategy to facilitate self-care patients with PID is community health nursing. Community health nursing has been found to be an effective risk reduction strategy in minority and low income adolescents. ${ }^{60-65}$ This strategy is most well-studied in the field of maternal child health. Community health nursing is associated with decreased rates of premature birth, ${ }^{60,62}$ cesarean sections, ${ }^{61}$ pregnancyinduced hypertension, ${ }^{62}$ longer infant hospitalizations, ${ }^{61}$ child injuries, ${ }^{62}$ and greater resource utilization and prenatal care visit attendance. ${ }^{63}$ Community health nursing has also shown promise in the field of STIs and HIV. Preliminary data from the Technology-Enhanced Community Health Nursing study have demonstrated that community health nursing combined with text messaging support is both feasible and acceptable for use in urban adolescents with PID. ${ }^{65}$ The program utilizes the Sister to Sister intervention, ${ }^{66}$ a CDC-approved evidencebased intervention along with text delivery of the 72 hours intervention by a trained community health nurse and text messaging support during the 14-day treatment period. While promising, research is ongoing to evaluate the impact of the intervention delivered by community health nurses on recurrent STIs after PID.

An additional gap in current PID prevention and treatment is the notification and treatment of male sexual partners. As mentioned earlier, recurrent PID is not uncommon and is associated with significant reproductive sequelae. If treatment efforts are focused solely on females, male sexual partners will continue to propagate infections. Both strategies that we propose, OUs and community health nurses, include risk reduction counseling, which includes counseling of females with PID on the importance of notifying their male sexual partners and referring them to treatment. Trent et $\mathrm{al}^{42}$ have shown that in pediatric ambulatory settings, an intervention, including nurse telephone follow-up at 24-48 hours and 2 weeks following discharge with PID diagnosis, was associated with high rates of partner notification and partner receipt of treatment. Additional research will need to be conducted to evaluate the effects of risk reduction counseling on male partner notification and treatment.

\section{Conclusion}

This review of the literature has identified the need for more vigilant screening for asymptomatic STIs in eligible female patients in order to prevent PID through early treatment of STIs with the goal of preventing damage to the reproductive tract that predisposes patients to infertility, ectopic pregnancy, 
and CPP. Importantly, behavioral interventions designed to improve provider and patient adherence to CDC treatment guidelines work, but must be widely implemented for improvement in population outcomes. The authors postulate that established interventions, such as OUs and community health nursing, used in new ways have promise for improving patient outcomes after PID.

\section{Acknowledgments}

Trainee and faculty time to develop and complete this review was funded in part with Federal funds from the National Institute of Nursing Research (R01NR013507), the Eunice Kennedy Shriver National Institute on Child Health and Human Development (T32HD052459), and the National Institute of Minority Health and Health Disparities (P20MD000198). The content is solely the responsibility of the authors and does not necessarily represent the official views of the National Institutes of Health.

\section{Disclosure}

MT is a member of the Trojan Sexual Advisory Council, currently receives unrestricted research funding through Johns Hopkins University from Hologic, Inc., and reports no conflicts of interest in this work. The other authors report no conflicts of interest in this work.

\section{References}

1. Sutton MY, Sternberg M, Zaidi A, St Louis ME, Markowitz LE. Trends in pelvic inflammatory disease hospital discharges and ambulatory visits, United States, 1985-2001. Sex Transm Dis. 2005;32(12):778-784.

2. CDC. PID Fact Sheet. Atlanta, GA: Department of Health and Human Services; 2007.

3. CDC. 2015 Sexually Transmitted Diseases Treatment Guidelines. Atlanta, GA: Department of Health and Human Services; 2015.

4. Trent M, Lehmann HP, Qian Q, Thompson CB, Ellen JM, Frick KD. Adolescent and parental utilities for the health states associated with pelvic inflammatory disease. Sex Transm Infect. 2011;87(7):583-587.

5. Wiesenfeld HC, Sweet RL, Ness RB, Krohn MA, Amortegui AJ, Hillier SL. Comparison of acute and subclinical pelvic inflammatory disease. Sex Transm Dis. 2005;32(7):400-405.

6. Peipert JF, Ness RB, Blume J, et al; Pelvic Inflammatory Disease Evaluation and Clinical Health Study Investigators. Clinical predictors of endometritis in women with symptoms and signs of pelvic inflammatory disease. Am J Obstet Gynecol. 2001;184(5):856-863.

7. Wiesenfeld HC, Hillier SL, Meyn LA, Amortegui AJ, Sweet RL. Subclinical pelvic inflammatory disease and infertility. Obstet Gynecol. 2012;120(1):37-43.

8. CDC. Pelvic Inflammatory Disease (PID). Atlanta, GA: Department of Health and Human Services; 2015.

9. CDC. Sexually Transmitted Disease Surveillance, 2013. Atlanta, GA: Department of Health and Human Services; 2014.

10. Trent M, Bass D, Ness RB, Haggerty C. Recurrent PID, subsequent STI, and reproductive health outcomes: findings from the PID evaluation and clinical health (PEACH) study. Sex Transm Dis. 2011;38(9):879-881.

11. Shafer MA, Sweet RL. Pelvic inflammatory disease in adolescent females. Epidemiology, pathogenesis, diagnosis, treatment, and sequelae. Pediatr Clin North Am. 1989;36(3):513-532.
12. Goyal M, Hersh A, Luan X, Localio R, Trent M, Zaoutis T. National trends in pelvic inflammatory disease among adolescents in the emergency department. J Adolesc Health. 2013;53(2):249-252.

13. Gray-swain MR, Peipert JF. Pelvic inflammatory disease in adolescents. Curr Opin Obstet Gynecol. 2006;18(5):503-510.

14. Berman SM, Hein K. Adolescents and STD's. In: Holmes KK, Sparling PF, Mardh PA, et al. editors. Sexually Transmitted Diseases. New York, NY: McGraw-Hill; 1999:129-142.

15. Peipert JF. Clinical practice. Genital chlamydial infections. $N$ Engl $J$ Med. 2003;349(25):2424-2430.

16. Cates W, Rolfs RT, ARAL SO. Sexually transmitted diseases, pelvic inflammatory disease, and infertility: an epidemiologic update. Epidemiol Rev. 1990;12(1):199-220.

17. Aral SO, Mosher WD, Cates W. Self-reported pelvic inflammatory disease in the United States, 1988. JAMA. 1991;266(18):2570-2573.

18. Grodstein F, Rothman KJ. Epidemiology of pelvic inflammatory disease. Epidemiology. 1994;5(2):234-242.

19. Simms I, Stephenson JM, Mallinson H, et al. Risk factors associated with pelvic inflammatory disease. Sex Transm Infect. 2006;82(6):452-457.

20. Aral SO, Mosher WD, Cates W. Self-reported pelvic inflammatory disease in the US: a common occurrence. Am J Public Health. 1985;75(10):1216-1218.

21. Cox S, Dean T, Posner SF, et al. Disparities in reproductive healthrelated visits to the emergency department in Maryland by age and race, 1999-2005. J Womens Health (Larchmt). 2011;20(12):1833-1838.

22. United States Census Bureau [webpage on the Internet]. How the Census Bureau Measures Poverty. Available from: http://www.census.gov/hhes/ www/poverty/about/overview/measure.html. Accessed June 9, 2016.

23. Leichliter JS, Chandra A, Aral SO. Correlates of self-reported pelvic inflammatory disease treatment in sexually experienced reproductiveaged women in the United States, 1995 and 2006-2010. Sex Transm Dis. 2013;40(5):413-418.

24. Haggerty CL, Gottlieb SL, Taylor BD, Low N, Xu F, Ness RB. Risk of sequelae after Chlamydia trachomatis genital infection in women. $J$ Infect Dis. 2010;201(suppl 2):S134-S155.

25. LeFevre ML; U.S. Preventive Services Task Force. Screening for chlamydia and gonorrhea: U.S. preventive services task force recommendation statement. Ann Intern Med. 2014;161(12):902-910.

26. Scholes D, Stergachis A, Heidrich FE, Andrilla H, Holmes KK, Stamm WE. Prevention of pelvic inflammatory disease by screening for cervical chlamydial infection. N Engl J Med. 1996;334(21):1362-1366.

27. Oakeshott P, Kerry S, Aghaizu A, et al. Randomised controlled trial of screening for Chlamydia trachomatis to prevent pelvic inflammatory disease: the POPI (prevention of pelvic infection) trial. $B M J$. 2010;340:c1642.

28. Hoover KW, Leichliter JS, Torrone EA, et al. Chlamydia screening among females aged 15-21 years - multiple data sources, United States, 1999-2010. MMWR Surveill Summ. 2014;63(suppl 2):80-88.

29. Cherpes TL, Wiesenfeld HC, Melan MA, et al. The associations between pelvic inflammatory disease, Trichomonas vaginalis infection, and positive herpes simplex virus type 2 serology. Sex Transm Dis. 2006;33(12):747-752.

30. Haggerty CL, Taylor BD. Mycoplasma genitalium: an emerging cause of pelvic inflammatory disease. Infect Dis Obstet Gynecol. 2011;2011:959816.

31. Wiesenfeld HC, Hillier SL, Krohn MA, et al. Lower genital tract infection and endometritis: insight into subclinical pelvic inflammatory disease. Obstet Gynecol. 2002;100(3):456-463.

32. Patton DL, Moore DE, Spadoni LR, Soules MR, Halbert SA, Wang SP. A comparison of the fallopian tube's response to overt and silent salpingitis. Obstet Gynecol. 1989;73(4):622-630.

33. Weström L, Joesoef R, Reynolds G, Hagdu A, Thompson SE. Pelvic inflammatory disease and fertility. A cohort study of 1,844 women with laparoscopically verified disease and 657 control women with normal laparoscopic results. Sex Transm Dis. 1992;19(4):185-192.

34. Trent M, Haggerty CL, Jennings JM, Lee S, Bass DC, Ness R. Adverse adolescent reproductive health outcomes after pelvic inflammatory disease. Arch Pediatr Adolesc Med. 2011;165(1):49-54. 
35. CDC. Pelvic Inflammatory Disease (PID) Treatment and Care. Atlanta, GA: Department of Health and Human Services; 2015.

36. Ness RB, Soper DE, Holley RL, et al. Effectiveness of inpatient and outpatient treatment strategies for women with pelvic inflammatory disease: results from the pelvic inflammatory disease evaluation and clinical health (PEACH) randomized trial. Am J Obstet Gynecol. 2002; 186(5):929-937.

37. Ness RB, Trautmann G, Richter HE, et al. Effectiveness of treatment strategies of some women with pelvic inflammatory disease: a randomized trial. Obstet Gynecol. 2005;106(3):573-580.

38. Smith KJ, Ness RB, Roberts MS. Hospitalization for pelvic inflammatory disease: a cost-effectiveness analysis. Sex Transm Dis. 2007;34(2):108-112.

39. CDC. Antibiotic Resistance Threats in the United States, 2013. Atlanta, GA: Department of Health and Human Services; 2014.

40. Trent M, Lehmann H, Butz A, Qian Q, Ellen JM, Frick KD. Clinician perspectives on management of adolescents with pelvic inflammatory disease using standardized patient scenarios. Sex Transm Dis. 2013;40(6):496-498.

41. Shih TY, Gaydos CA, Rothman RE, Hsieh YH. Poor provider adherence to the Centers for Disease Control and Prevention treatment guidelines in US emergency department visits with a diagnosis of pelvic inflammatory disease. Sex Transm Dis. 2011;38(4):299-305.

42. Trent M, Judy SL, Ellen JM, Walker A. Use of an institutional intervention to improve quality of care for adolescents treated in pediatric ambulatory settings for pelvic inflammatory disease. JAdolesc Health. 2006;39(1):50-56.

43. Goyal M, Hersh A, Luan X, Localio R, Trent M, Zaoutis T. Are emergency departments appropriately treating adolescent pelvic inflammatory disease? JAMA Pediatr. 2013;167(7):672-673.

44. Woods JL, Scurlock AM, Hensel DJ. Pelvic inflammatory disease in the adolescent: understanding diagnosis and treatment as a health care provider. Pediatr Emerg Care. 2013;29(6):720-725.

45. Mccallum CA, Oman KS, Makic MB. Improving the assessment and treatment of pelvic inflammatory disease among adolescents in an urban children's hospital emergency department. J Emerg Nurs. 2014;40(6):579-585.

46. Dunbar-Jacob J, Sereika SM, Foley SM, Bass DC, Ness RB. Adherence to oral therapies in pelvic inflammatory disease. JWomens Health (Larchmt). 2004;13(3):285-291.

47. Trent M, Ellen JM, Frick KD. Estimating the direct costs of pelvic inflammatory disease in adolescents: a within-system analysis. Sex Transm Dis. 2011;38(4):326-328.

48. Baugh CW, Venkatesh AK, Bohan JS. Emergency department observation units: a clinical and financial benefit for hospitals. Health Care Manage Rev. 2011;36(1):28-37.

49. Ross MA, Graff LG. Presenting the observation unit concept to administration and payers. In: Graff LG, editor. Observation Units Implementation and Management Strategies. Dallas, TX: American College of Emergency Physicians; 1998:7-20.

50. Cooke MW, Higgins J, Kidd P. Use of emergency observation and assessment wards: a systematic literature review. Emerg Med J. 2003;20(2): $138-142$.

51. Decker WW, Smars PA, Vaidyanathan L, et al. A prospective, randomized trial of an emergency department observation unit for acute onset atrial fibrillation. Ann Emerg Med. 2008;52(4):322-328.
52. Farkouh ME, Smars PA, Reeder GS, et al. A clinical trial of a chest-pain observation unit for patients with unstable angina. Chest pain evaluation in the emergency room (CHEER) Investigators. $N$ Engl J Med. 1998;339(26):1882-1888.

53. Ross MA, Hockenberry JM, Mutter R, Barrett M, Wheatley M, Pitts SR. Protocol-driven emergency department observation units offer savings, shorter stays, and reduced admissions. Health Aff (Millwood). 2013;32(12):2149-2156.

54. Sheehy AM, Graf B, Gangireddy S, et al. Hospitalized but not admitted: characteristics of patients with "observation status" at an academic medical center. JAMA Intern Med. 2013;173(21):1991-1998.

55. Centers for Medicare and Medicaid. CMS Manual System. Atlanta, GA: Department of Health and Human Services; 2014.

56. Centers for Medicare and Medicaid. CMS Manual System. Atlanta, GA: Department of Health and Human Services; 2005.

57. Lane RD, Sandweiss DR, Corneli HM. Treatment of skin and soft tissue infections in a pediatric observation unit. Clin Pediatr (Phila). 2014;53(5):439-443.

58. McDermott MF, Murphy DG, Zalenski RJ, et al. A comparison between emergency diagnostic and treatment unit and inpatient care in the management of acute asthma. Arch Intern Med. 1997;157(18):2055-2062.

59. Hill A, Anders J, Chung S, et al. How Long Is This Going To Take, Doc? Impact of Wait Time \& Length of Stay on Patient Satisfaction and Medication Adherence for Adolescents with Pelvic Inflammatory Disease. San Diego, CA: Pediatric Academic Societies; Abstract; 2015.

60. Nguyen JD, Carson ML, Parris KM, Place P. A comparison pilot study of public health field nursing home visitation program interventions for pregnant Hispanic adolescents. Public Health Nurs. 2003;20(5):412-418.

61. Koniak-griffin D, Mathenge C, Anderson NL, Verzemnieks I. An early intervention program for adolescent mothers: a nursing demonstration project. J Obstet Gynecol Neonatal Nurs. 1999;28(1):51-59.

62. Kitzman H, Olds DL, Henderson CR, et al. Effect of prenatal and infancy home visitation by nurses on pregnancy outcomes, childhood injuries, and repeated childbearing. A randomized controlled trial. JAMA. 1997;278(8):644-652.

63. Flynn L, Budd M, Modelski J. Enhancing resource utilization among pregnant adolescents. Public Health Nurs. 2008;25(2):140-148.

64. Mcnaughton DB. Nurse home visits to maternal-child clients: a review of intervention research. Public Health Nurs. 2004;21(3):207-219.

65. Trent ME, Chung SE, Gaydos C, Anders J, Rothman R, Butz A. Urban minority youth participation in clinical research: testing the design of the TECH-N trial. J Adolesc Health. 2015;56(2):S25-S26.

66. Jemmott LS, Jemmott JB, Hutchinson MK, Cederbaum JA, O'leary A. Sexually transmitted infection/HIV risk reduction interventions in clinical practice settings. J Obstet Gynecol Neonatal Nurs. 2008; 37(2):137-145.

67. Bevan CD, Ridgway GL, Rothermel CD. Efficacy and safety of azithromycin as monotherapy or combined with metronidazole compared with two standard multidrug regimens for the treatment of acute pelvic inflammatory disease. J Int Med Res. 2003;31:45-54.

68. Savaris RF, Teixeira LM, Torres TG, et al. Comparing ceftriaxone plus azithromycin or doxycycline for pelvic inflammatory disease: a randomized controlled trial. Obstet Gynecol. 2007;110:53-60.
Infection and Drug Resistance

\section{Publish your work in this journal}

Infection and Drug Resistance is an international, peer-reviewed openaccess journal that focuses on the optimal treatment of infection (bacterial, fungal and viral) and the development and institution of preventive strategies to minimize the development and spread of resistance. The journal is specifically concerned with the epidemiology of antibiotic resistance and the mechanisms of resistance development and diffusion in both hospitals and the community. The manuscript management system is completely online and includes a very quick and fair peerreview system, which is all easy to use. Visit http://www.dovepress.com/ testimonials.php to read real quotes from published authors. 